\title{
Overcoming challenges in order to improve the management of rheumatic and musculoskeletal diseases across the globe
}

\author{
Anthony D. Woolf • Sherine Gabriel
}

Received: 5 January 2015 / Accepted: 5 January 2015 / Published online: 21 February 2015

(C) International League of Associations for Rheumatology (ILAR) 2015

The challenges faced in improving the prevention and management of rheumatic and musculoskeletal diseases (RMDs) across the globe are addressed in the inaugural White Paper from the World Forum on Rheumatic amd Musculoskeletal Diseases (WFRMD) published in this issue [1]. The WFRMD, convened by Dr Mustafa Al Maini, brings together leaders from the international rheumatological community who are committed to promoting collaborative strategies to deal with this burden and work with major organisations such as ILAR, ACR, EULAR, PANLAR and AFLAR and policy makers such as the World Health Organisation (WHO). It is an important and timely initiaitive to increase awareness of the major burden that rheumatic and musculoskeletal diseases have on individuals and society and to explore opportunities to address these challenges on a local and global scale. This is the mission of WFRMD (www.wfrmd.org). It fits within the context of the Global Alliance for Musculoskeletal Health which the Bone and Joint Decade has brought together to call for action by policy makers to deal with the burden of RMDs (http://bjdonline.org).

Musculoskeletal health is essential to independent living and self-sustainability as well as enabling people to keep physically active and reduce the risk of non-communicable diseases. It is threatened by a wide range of RMDs at all stages of life. Other risks such as obesity, injuries related to occupation and sports and more serious trauma such as falls and road

\footnotetext{
A. D. Woolf $(\bowtie)$

Global Alliance for Musculoskeletal Health of the Bone and Joint Decade, University of Plymouth Peninsula College of Medicine and Dentistry, Plymouth, England, UK

e-mail: anthony.woolf@btopenworld.com

S. Gabriel

Mayo Clinic, Rochester, MN, USA
}

injuries can often result in musculoskeletal disability. These RMDs are often long term and are an important comorbidity amongst the chronic diseases we accumulate as we age. An RMD as a comorbidity magnifies the physical disability that people suffer [2]. All these factors affecting musculoskeletal health along with the ageing of populations result in the great and growing prevalence and disability across the globe [3].

Further, exacerbating these trends is the growing need for people, as they age, to be able to continue to contribute economically to society with delayed retirement ages becoming commonplace in many countries around the world. Health and social care systems are struggling to cope with ageing populations and their multimorbidity. For these reasons, there is an urgency to deal with the challenges of rheumatic and musculoskeletal diseases, challenges which are not currently being addressed by policies and priorities of health systems around the globe [4]. Indeed, RMDs are not considered a major noncommunicable disease by the WHO [5] or UN [6]. As a consequence, there is great and growing avoidable disability. The Bone and Joint Decade has responded by bringing together all stakeholders - professional, scientific and patient organisations as a Global Alliance for Musculoskeletal Health calling for action by decision makers to implement policies to deal with this burden (http://bjdonline.org/call-for-action/). The specific challenges and opportunities for the rheumatology community have been considered by the inaugural meeting of the World Forum on Rheumatic and Musculoskeletal Diseases on the 26th of September in Abu Dhabi and are reported in this issue [1]. Subsequent papers are planned to address issues raised in the White Paper. This is much needed as the expert community must propose solutions for the decision makers to deal with these challenges.

The burden of RMDs on individuals and societies is now well documented [3, 7-15], and there are many evidence- 
based guidelines giving effective means of prevention, management and rehabilitation [16]. There are models of care for many RMDs showing how the evidence can be implemented. There are numerous surveys showing this is not happening equitably across and between countries for the various RMDs. For example, the access to and outcome of treatment for rheumatoid arthritis relates to GDP [17]. The management of musculoskeletal pain is poor [18]. Why is there not the appropriate priority and policies for RMDs commensurate with their burden? Despite the large and growing body of evidence, policy makers are not aware of the burden of RMDs and of what can now be achieved through prevention and control. People continue to accept many of these conditions as a normal consequence of ageing or something they should quietly cope with. The variety of health-care professions and disciplines who may deal with someone with an RMD receive limited education and training about their assessment and management. There is a wide spectrum of conditions within RMDs with various specialist professions and disciplines managing them and different patient organisations lobbying for them. This lack of cohesiveness does not help with promoting the key message of the scale of the problem and need for action. That is why initiatives that bring all the stakeholders together, such as the WFRMD and the Bone and Joint Decade, which brings together a wider group of professions dealing with RMDs within a global alliance, are so important in pushing for change.

However, just demanding priority commensurate with burden is not enough. We must articulate what we want and what will make a real difference to the health of our patients and populations. The WFRMD has carefully considered the issues and identifies key areas. A major area identified is access to appropriate services, which includes appropriately skilled healthcare workers, diagnostics and therapies. There is a lack of clinical competencies in most countries. Medical students learn little about RMDs, and they lack clinical skills for assessment and diagnosis [19]. Primary care physicians often lack specific training in RMDs despite $20 \%$ of adults consulting them each year with a musculoskeletal problem accounting for one in six GP consultations in the UK [20]. Advances in management of various RMDs require early diagnosis and early use of complex interventions. But there is a shortage of healthcare professionals who are able to recognise these conditions in the community and a lack of specialists who can provide the tight management they require to achieve the outcomes that are now possible. Increasing the competencies of first-line health workers such as primary care physicians and community-based clinical officers in low-income countries will improve the management of common RMDs and the identification and referral of those with inflammatory arthritis. The UWEZO Programme in Kenya [21] is aimed at achieving this. This however will further highlight the need for those with greater competencies to be able to provide a higher level of management. Access to diagnostics is important but there will be different sensitivities and specificities in some populations where there are high incidences of infections and challenges with technical quality. In these settings, there is more dependence on clinical skills and opportunities for techniques such as ultrasound to identify synovitis and help with diagnosing and assessing inflammatory arthritis.

The nature of these challenges are considered in the White Paper, and the need to increase access to paediatric and adult rheumatologists identified as of high importance and a major challenge highlighted by Al Maini and colleagues [1]. Many parts of the world are devoid of rheumatologists. Very often, people with RMDs are managed by specialists in other disciplines who do not have the training or experience in the care of these conditions; thus, the appropriateness of management is not clear. Increasing the number of rheumatologists across the globe will, however, be a costly challenge, especially given the global shortage of physicians and other health professionals. Ensuring specialists offer equitable access within countries is also a challenge as most congregate in urban areas. A first step is to ensure all doctors have appropriate basic competencies in dealing with RMDs, and core recommendations for undergraduate curriculae have been made [22] and need to be implemented by all medical schools. Primary care physicians should gain far greater competency in diagnosing and managing RMDs. Models of care highlight the need for networks of the different health professionals and disciplines to work together around the patient pathway if care is to be optimised [23]. Maintaining quality of care is important, and this is accomplished by maintaining the competencies of the workforce through CME and CPD as well as audit tools such as those developed by the eumusc.net project [24-27] to ensure physicians are delivering and patients are receiving the best standards of care.

Finally, we do not have all the answers. The White Paper highlights the need to support the development of investigator-lead research, and there are excellent examples of successful mentoring schemes such as the USBJI Young Investigator Program which has led to many successful grants [28]. Such mentoring needs to be available for researchers in low- to middle-income countries to develop research programmes relevant to their populations and their clinical challenges. This will also increase the research skills and capacity in such countries. Clinical trials have been a core part of rheumatology research and have successfully taken many innovations from bench to bedside. Rheumatology very early developed outcome tools to facilitate the development of treatments. It is important that clinicians in all settings can evaluate the effectiveness of interventions in those populations. With the move to personalised medicine, we may need to be rethinking whether evidence is as transferrable from one person or population to another as we had assumed. We also need a better understanding of the impact of RMDs and the efficacy 
and safety of interventions in all populations, and there are excellent examples of epidemiological research such as COPCORD surveys [29] and drug registries from which we can learn a lot.

Clearly, there are many challenges. However, as discussed in the White Paper, there are also some clear steps the RMD community can take to move forward. To make these steps a reality, we must also change the policy context nationally and internationally. To that end, the Bone and Joint Decade is working with WHO to ensure its policies and strategies reflect the burden of RMDs. We have to highlight the central importance of mobility and dexterity for healthy and independent lives. The Bone and Joint Decade has launched a call for action by policy makers to address the burden of RMDs which you can show your support for (http://bjdonline.org/epetition/2. The WFRMD has clearly laid out the challenges and we urge you to read the White Paper in this issue [1] and follow the forum's website (www.wfrmd.org). We must all work together as a Global Alliance for Musculoskeletal Health to overcome these challenges.

Disclosures None.

\section{References}

1. Al Maini M, Adelowo F, Al Saleh J, Al Weshahi Y, Burmester GR, Cutolo M, et al. (2015) The Global Challenges and Opportunities in the Practice of Rheumatology: White Paper by the World Forum on Rheumatic and Musculoskeletal Diseases. Clinical Rheumatology

2. Loza E, Jover JA, Rodriguez L, Carmona L (2009) Multimorbidity: prevalence, effect on quality of life and daily functioning, and variation of this effect when one condition is a rheumatic disease. Semin Arthritis Rheum 38(4):312-9

3. Vos T, Flaxman AD, Naghavi M, Lozano R, Michaud C, Ezzati M et al (2010) Years lived with disability (YLDs) for 1160 sequelae of 289 diseases and injuries 1990-2010: a systematic analysis for the Global Burden of Disease Study 2010. Lancet 380(9859):2163-96

4. Woolf AD (2012) The Bone and Joint Decade report: working together to make musculosekeltal conditions a public health priority. Arthritis Research UK Topical Reviews Series 6 Issue 12. http:// www.arthritisresearchuk.org/health-professionals-and-students/ reports/topical-reviews/topical-reviews-summer-2012.aspx

5. Global Action for the Prevention and Control of NCDs 2013-2020. Geneva: World Health Organisation. http://apps.who.int/iris/ bitstream/10665/94384/1/9789241506236_eng.pdf?ua=1

6. Prevention and Control of Non-communicable Diseases. Report of the Secretary-General. United Nations Report A66/83 (2011). www. un.org/en/ga/search/view_doc.asp?symbol=A/66/83\&Lang=E

7. The European musculoskeletal conditions surveillance and information network http://www.eumusc.net/

8. Cross M, Smith E, Hoy D, Nolte S, Ackerman I, Fransen M et al (2014) The global burden of hip and knee osteoarthritis: estimates from the global burden of disease 2010 study. Ann Rheum Dis 73(7): 1323-30

9. Cross M, Smith E, Hoy D, Carmona L, Wolfe F, Vos T et al (2014) The global burden of rheumatoid arthritis: estimates from the global burden of disease 2010 study. Ann Rheum Dis 73(7):1316-22
10. Hoy DG, Smith E, Cross M, Sanchez-Riera L, Blyth FM, Buchbinder R, Woolf AD, Driscoll T, Brooks P, March LM (2015) Reflecting on the global burden of musculoskeletal conditions: lessons learnt from the Global Burden of Disease 2010 Study and the next steps forward. Ann Rheum Dis 74(1):4-7

11. Hoy D, March L, Brooks P, Blyth F, Woolf A, Bain C et al (2014) The global burden of low back pain: estimates from the Global Burden of Disease 2010 study. Ann Rheum Dis 73(6):968-74

12. Hoy D, March L, Woolf A, Blyth F, Brooks P, Smith E et al (2014) The global burden of neck pain: estimates from the global burden of disease 2010 study. Ann Rheum Dis 73(7):1309-15

13. Hoy DG, Smith E, Cross M, Sanchez-Riera L, Buchbinder R, Blyth FM et al (2014) The global burden of musculoskeletal conditions for 2010: an overview of methods. Ann Rheum Dis 73(6):982-9

14. Smith E, Hoy D, Cross M, Merriman TR, Vos T, Buchbinder R et al (2014) The global burden of gout: estimates from the Global Burden of Disease 2010 study. Ann Rheum Dis 73(8):1470-6

15. Smith E, Hoy DG, Cross M, Vos T, Naghavi M, Buchbinder R et al (2014) The global burden of other musculoskeletal disorders: estimates from the Global Burden of Disease 2010 study. Ann Rheum Dis 73(8):1462-9

16. Woolf AD. European action towards better musculoskeletal health: a guide to the prevention and treatment of musculoskeletal conditions for the healthcare practitioner and policy maker (2005). Lund, Sweden

17. Sokka T, Kautiainen H, Pincus T, Toloza S, da Rocha Castelar PG, Lazovskis J et al (2009) Disparities in rheumatoid arthritis disease activity according to gross domestic product in 25 countries in the QUEST-RA database. Ann Rheum Dis 68(11):1666-72

18. Woolf AD, Zeidler H, Haglund U, Carr AJ, Chaussade S, Cucinotta D et al (2004) Musculoskeletal pain in Europe: its impact and a comparison of population and medical perceptions of treatment in eight European countries. Ann Rheum Dis 63(4):342-7

19. Chehade MJ, Bachorski A (2008) Development of the Australian core competencies in musculoskeletal basic and clinical science project—phase 1. Med J Aust 189(3):162-5

20. Arthritis Research UK Primary Care Centre http://www. arthritisresearchuk.org/research/our-centres-of-excellence/primarycare-centre.aspx

21. Erwin J, Woolf AD, Cederlund I, Oyoo O, Mwaniki L, Etau P (2014) UWEZO - Musculoskeletal Health Training in Kenya. Clinical Rheumatology In Press

22. Woolf AD, Walsh NE, Akesson K (2004) Global core recommendations for a musculoskeletal undergraduate curriculum. Ann Rheum Dis 63(5):517-24

23. Ferli E, McGivern G, Dopson S, Fitzgerald L (2013) Making wicked problems governable? The case of managed networks in healthcare. Oxford University Press

24. EUMUSC.net Standards of Care www.eumusc.net/workpackages wp5.cfm

25. EUMUSC.net healthcare quality indicators www.eumusc.net/ workpackages_wp6.cfm

26. Petersson IF, Strombeck B, Andersen L, Cimmino M, Greiff R, Loza E et al (2014) Development of healthcare quality indicators for rheumatoid arthritis in Europe: the EUMUSC.net project. Ann Rheum Dis 73(5): $906-8$

27. Stoffer MA, Smolen JS, Woolf A, Ambrozic A, Bosworth A, Carmona L et al (2014) Development of patient-centred standards of care for rheumatoid arthritis in Europe: the EUMUSC.net project. Ann Rheum Dis 73(5):902-5

28. US Bone \& Joint Initiative Young Investigator Program http://usbjd. org/research/research_op.cfm?dirID $=197$

29. Chopra A (2013) The COPCORD world of musculoskeletal pain and arthritis. Rheumatology (Oxford) 52(11):1925-8 